\section{Value-added Frontiers programme}

Sir - As a new member of the Council of Scientists of the Human Frontiers Science Program (HFSP), I was interested to read your recent leading article and News story (Nature 386, 95 \& 100; 1997).

As you correctly point out, some research requires major investment in one facility, and this must be funded internationally. CERN is the prime example, and it is good that Tokyo has agreed to contribute. However, although I agree that particle physics is qualitatively different from research on the brain, it is true that international collaboration can provide added value to national programmes. This is particularly true in a multidisciplinary research area such as brain research, where different countries may contribute complementary expertise. The HFSP, with relatively modest funds, achieves this superbly.

In the programme, the necessity for international collaboration is a major factor taken into account by review committees in assessing grant applications. Further, to demonstrate that the programme actually succeeds in its internationalist aims, we can cite the General Review, in which grant recipients and those just below the cut-off point were interviewed:

"Only three per cent of the unsuccessful applicants reported that they were able to carry out exactly the same research and collaboration without the HFSP grant... . Although roughly half the unsuccessful applicants said they were able to do some of the intended research and collaboration without HFSP support, they were able to do significantly less collaboration (or none) and the scope of the research was diminished. The remaining half reported that they were not able to carry out any of the proposed research or collaboration at all."

That there is an increasing globalization of scientific research seems without doubt. The foregoing testimonies indicate that the HFSP is having an important impact on international science over and above the possibilities offered by the national funding agencies.

In Richard Nathan's News article, an anonymous British researcher complains that it is easier to obtain funds in the United Kingdom than from the HFSP and that funds should not therefore be diverted. This is a Catch-22 argument. The review committees consider that many of the applications not funded do fulfil the requirements of scientific quality and the need for international collaboration. The ability of the HFSP to carry out a 'value added' role, in a way that national agencies do not, is a powerful argument for an increase in financial support.

\section{Tom Blundell}

University of Cambridge,

Department of Biochemistry,

Tennis Court Road,

Cambridge CB2 1QW, UK

\section{Ginkgo thrives}

Sir - A recent News story described a report which concludes that the increasing popularity of herbal medicine in the Western world is threatening its natural base, medicinal plants growing in the wild (Nature 385, 570; 1997). It also refers to Germany as being the largest consumer of these medicinal plants, and focuses mainly on the ginkgo tree as an example of such a plant threatened by overuse.

This company, Dr Willmar Schwabe Arzneimittel, is a leading manufacturer of plant-based pharmaceuticals. Ginkgo leaves are indeed the source of the company's most outstanding product. It is a highly refined extract 'Egb 761', the active ingredient of a preparation sold the world over under trademarks such as Tebonin, Tanakan, Tebokan, Tebofortran and Rökan. These products are successfully used in the treatment of cognition and memory impairment as well as vascular and Alzheimer-type dementia.

To meet the rising demand for ginkgo leaves, we established our own ginkgo plantations near the Atlantic coast of France and in South Carolina in the United States in 1982, together with the BeaufourIpsen Group, our French partner.

Twenty-five million trees growing on 1,000 hectares of land on these two sites are producing close to 4,000 tonnes of dried leaves a year. (The author mentions a figure of 2,000 tonnes being consumed in Germany.) In addition, more than 25 million trees are cultivated in China for the same purpose. Specific cultivation techniques for propagation, nursing and harvesting have been developed to meet the specific needs of this unconventional crop. In this way, we do our best to safeguard the natural resources of ginkgo. At the same time, we are assured of a raw material of high standard, produced under ecologically sound and well monitored conditions.

Ginkgo is also cultivated in Japan and South Korea, and is used worldwide as an ornamental tree which, incidentally, is resistant to urban pollution. For some time it was disputed whether ginkgo biloba still occurred under natural conditions but Chinese researchers have shown that it grows in natural mountainous forests in the Chinese provinces of Anhui, Zhejiang and Guizhou. So the ginkgo tree is by no means a threatened species. If it has become less abundant, there are probably other reasons than the mere gathering of its leaves.

To develop a new product in the pharmaceutical industry costs millions of dollars before it even reaches the market. It would not make sense for us to make such large investments if we were not sure of the resource base. Any investment based on a resource plant threatened by extinction would be meaningless.

\section{Wilhelm Schmid}

Dr Willmar Schwabe GmbH \& Co.,

Postfach 4109 25,

76209 Karlsruhe, Germany

\section{Todd's achievement}

Sir - Lord Todd ("Tod Almighty" to his students) would have appreciated John Maddox's obituary of him (Nature 385, 492; 1997).

Allow me to make two corrections. Todd did not isolate the active constituent in cannabis. He isolated cannabinol, which is barely active. Most of the cannabinol in hashish (or possibly all of it) is an oxidation product of other constituents. Todd knew this and mentioned it in his autobiography.

The active constituent of cannabis is $\Delta$-9-THC which Y. Gaoni and I isolated and elucidated the structure of in the 1960s (J. Am. Chem. Soc. 86, 1646; 1964). We and others did quite a bit of work on it and today there are thousands of papers on THC. Burstein and I reported the first step of THC metabolism in Nature (225, 87-88; 1970) and J. Am. Chem. Soc. (92, 3468-3469; 1970).

When we identified arachidonoylethanolamide (anandamide) as the endogenous brain ligand that binds to the cannabinoid receptor (Science 258, 1946-1949; 1992) Todd was delighted.

Raphael Mechoulam

Hebrew University of Jerusalem,

Faculty of Medicine,

Ein Kerem,

Jerusalem 91120, Israel

\section{correction}

Christine Clayton's letter (Nature 386, 432; 1997) about spelling mistakes and grammatical errors contained a grammatical error introduced in the Nature office. The fourth sentence read: "Last year, a paper I had submitted was returned by the journal concerned complaining that it was 'strewn with spelling mistakes and grammatical errors'." It should have read: "Last year, a paper I had submitted to a North American journal was returned with accusations that it was 'strewn with spelling mistakes and grammatical errors." -Editor, Nature. 